\title{
Surface Modification of Polystyrene by Femtosecond Laser Irradiation
}

\author{
B. Wang ${ }^{1,2}$, X. C. Wang ${ }^{1,3}$, H. Y. Zheng ${ }^{1,3}$, and Y. C. Lam ${ }^{1,2}$ \\ ${ }^{1}$ SIMTech-NTU Joint Laboratory (Precision Machining), Nanyang Technological University, 50 \\ Nanyang Avenue, Singapore 639798; \\ E-Mail: wangbing@ntu.edu.sg \\ ${ }^{2}$ School of Mechanical \& Aerospace Engineering, Nanyang Technological University, 50 Nanyang \\ Avenue, Singapore 639798; \\ E-Mails: myclam@ntu.edu.sg \\ ${ }^{3}$ Singapore Institute of Manufacturing Technology (SIMTech), 71 Nanyang Drive, Singapore, \\ 638075; \\ E-Mail: xcwang@SIMTech.a-star.edu.sg; hyzheng@SIMTech.a-star.edu.sg
}

In this paper, the effect of laser fluence on polystyrene (PS) surface wettability was investigated. It was found that the PS surface could be modified into highly hydrophilic with water contact angle (WCA) of $12.7^{\circ}$ from the original WCA of $88.2^{\circ}$ with micro-pits created on the surface. It was also found that the laser texturing process had a negligible effect on the transparency of the laser textured PS substrate probably due to the shallow surface structure created. The effect of various laser parameters on the micro-pits structures was investigated. The correlation between the surface water contact angle and the micro-pits structures has been attempted.

DOI: $10.2961 /$ jlmn.2016.02.0017

Keywords: femtosecond laser, polystyrene (PS), wettability, transparency, micro-pits, surface texturing and surface modification

\section{Introduction}

Polymer surface wettability modification to either hydrophilic or hydrophobic has various applications. For instance, a hydrophilic surface can improve the surface wettability and adhesion, which can be applied in coating and joining applications. A super-hydrophobic surface with low hysteresis has a self-cleaning function, which is similar to the lotus leaf surface. Polymer surface modification has become an actively studied area recently [1-4]. Polystyrene (PS) is a widely used polymer in biotechnologies and microfluidics. Controlled surface wettability modification of PS is highly desirable for PS based biomedical and microfluidic devices. Different treatment methods can be used for polymer surface modification, such as the electron beam irradiation[5], plasma treatment $[6 ; 7]$, ion beam treatment $[8 ; 9]$ corona discharges [10], wet-chemical etching [11], and laser irradiation. Laser irradiation is a noncontact clean technique compared with other surface treatment methods. Ultrashort pulsed laser are increasingly employed for polymer surface treatment recently due to its short pulse duration and high laser intensity. The thermal effect is minimized and it can treat the material in a localized position with high precision. Owning to its high laser intensity, it can be applied to treat different materials including polymers, metals and semiconductors [12-18]. In this investigation, we demonstrated that infrared femtosecond laser could induce highly hydrophilicity on PS material surface through laser direct irradiation under different process parameters. The effects of laser fluence on surface morphology and its surface wettability were investigated.

\section{Experimental set-up}

A commercial polystyrene sheet with a thickness of 1.2 $\mathrm{mm}$ was used in the experiments. The PS samples were treated with a Ti:Sapphire based fs laser (Quantronix integra-C, USA) with a central wavelength of $795 \mathrm{~nm}$. The laser pulse duration was $130 \mathrm{fs}$ with a maximum power output of $1.5 \mathrm{~W}$ and the repetition rate was fixed at $1 \mathrm{KHz}$. The beam profile was approximately Gaussian and it was focused to the sample surface by a Scanlab galvanometer scanner. The focal spot size was around $30 \mu \mathrm{m}$ in diameter. The laser treatments were conducted in an ambient air environment at room temperature of around $21^{\circ} \mathrm{C}$ and relative humidity of around $60 \%$. The PS sample surface was treated under different laser fluence. The surface properties after laser treatment were analyzed using X-ray photoelectron spectroscopy (XPS) (ESCALAB 250Xi, Thermo Scientific, UK), optical microscope (ZEISS Axioskop 2 MAT) and optical profilometer (Alicona, USA). A sessile drop method was applied in the surface water contact angle (WCA) measurement. WCA was measured by using VCA Optima (VCA-2500XE AST Products, Inc. USA) with a fixed water droplet size of $1 \mu \mathrm{l}$.

\section{Experimental results and discussion}

PS surface was scanned at a high scanning speed: 200 $\mathrm{mm} / \mathrm{s}$ with a fixed repetition rate at $1 \mathrm{KHz}$. The hatching line spacing was fixed at $200 \mu \mathrm{m}$. A matrix of pits was created with pitch density of $200 \mu \mathrm{m}$. The laser fluence was varied from $1.5 \mathrm{~J} / \mathrm{cm}^{2}$ to $193.9 \mathrm{~J} / \mathrm{cm}^{2}$. The effect of laser fluence on water contact angle was shown in Fig.1. As laser fluence increased the surface water contact angle decreased to highly hydrophilic (around $12.7^{\circ}$ ) from original $88.2^{\circ}$, this was due to the created pits on the surface. With pits 
created on the surface, water droplet can easily penetrate into the surface. Thus the surface became hydrophilic. The effect of laser fluence on the size and depth of the pits was depicted in Fig. 2. The radius of pits increased from 8.86 $\mu \mathrm{m}$ to $21.04 \mu \mathrm{m}$ as fluence increased from $4.8 \mathrm{~J} / \mathrm{cm}^{2}$ to $36.6 \mathrm{~J} / \mathrm{cm}^{2}$. The depth of pit was increased from $0.98 \mu \mathrm{m}$ to $2.79 \mu \mathrm{m}$ with fluence increased from $4.8 \mathrm{~J} / \mathrm{cm}^{2}$ to 36.6 $\mathrm{J} / \mathrm{cm}^{2}$. Since the depth of pits was pretty small, the transparency of material was maintained after laser treatment which will be discussed later.

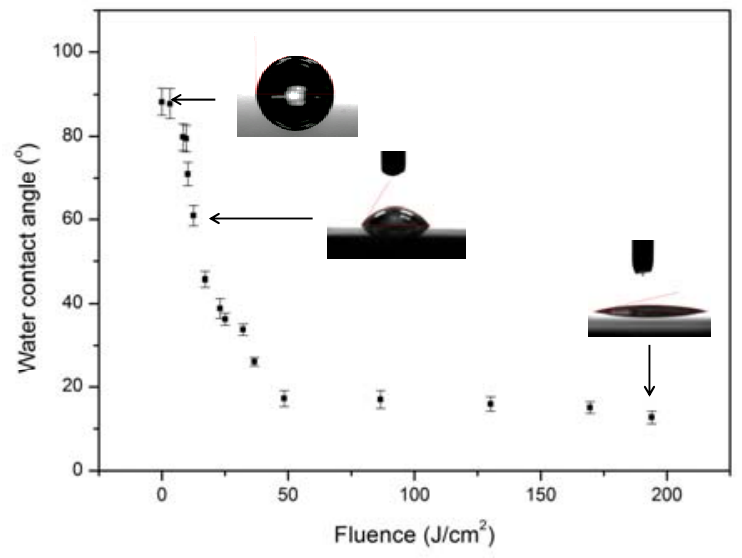

Fig. 1 Surface water contact angle at different laser fluence.

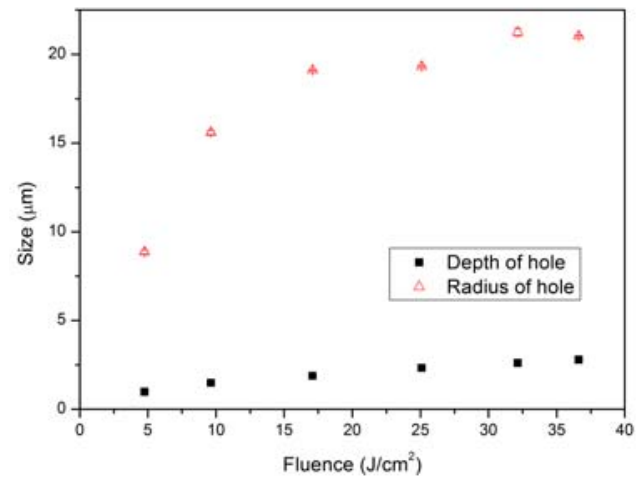

Fig. 2 Radius and depth of pits at different laser fluence.

As shown in Fig.2, the radius and depth of pit increased with laser fluence. The increased size of pit further influenced the water contact angle of PS surface. The effect was shown in Fig.3. The increasing radius and depth of pit made the water droplet easier to penetrate into the surface. Thus the surface became more hydrophilic as the size of pit increased. The water contact angle decreased to around $20^{\circ}$ when the depth of pit increased to $2.79 \mu \mathrm{m}$.

The effect of the pit matrix density on surface wettability was also investigated as shown in Fig.4. The scanning speed was varied from $200 \mathrm{~mm} / \mathrm{s}$ to $700 \mathrm{~mm} / \mathrm{s}$, and the spacing between the pits was varied from $200 \mu \mathrm{m}$ to 700 $\mu \mathrm{m}$. The water contact angle increased from $15^{\circ}$ to $80^{\circ}$ as the spacing between the pits increased from $200 \mu \mathrm{m}$ to 700 $\mu \mathrm{m}$.

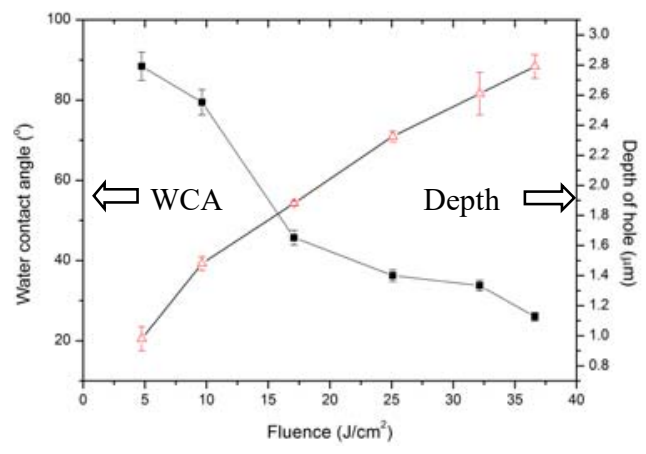

Fig. 3 The changing of WCA and depth of pit with laser fluence.

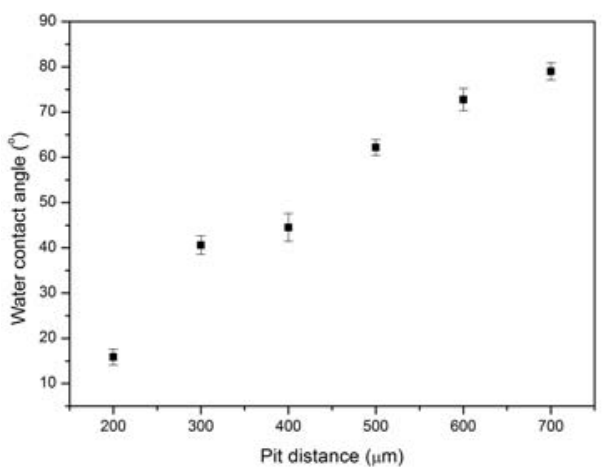

Fig. 4 Effect of pit distance on surface WCA
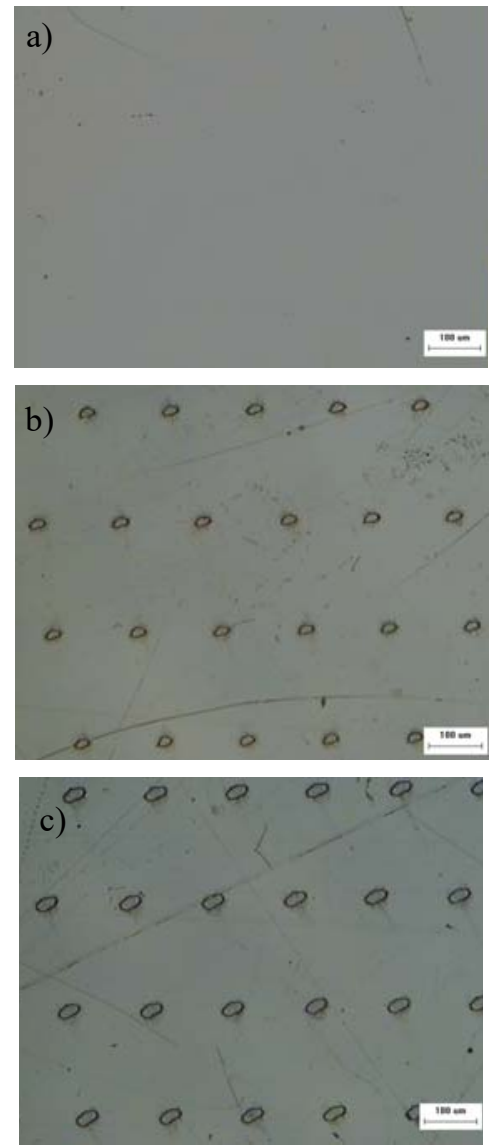

Fig. 5 Pits created under different laser fluence at a) $0 \mathrm{~J} / \mathrm{cm}^{2}$ b) $23.1 \mathrm{~J} / \mathrm{cm}^{2}$ and c) $48.4 \mathrm{~J} / \mathrm{cm}^{2}$ measured by an optical microscope. The scanning speed was fixed at $200 \mathrm{~mm} / \mathrm{s}$ with hatching density at $200 \mu \mathrm{m})$. 
As shown in Fig. 5, the laser treatment created micropits array surface pattern on the originally-hydrophilic PS surface with a WCA of around 88.20. The micro-pits pattern increased the surface roughness even though most of the material area is unprocessed, so the water droplet can easily penetrate into the surface and the surface becomes more hydrophilic and even super hydrophilic. This is following Wenzel's model that surface roughness amplifies the wettability, which means that with increasing surface roughness, a hydrophilic surface will become more hydrophilic and even superhydrophilic and a hydrophobic surface will become more hydrophobic and even superhydrophobicity.

One advantage of this method is that the material maintains highly transparent after laser treatment as shown in Fig. 6. Six areas inside the red rectangular were treated at different laser fluence: $193.9 \mathrm{~J} / \mathrm{cm}^{2}, 169.5 \mathrm{~J} / \mathrm{cm}^{2}, 130.2$ $\mathrm{J} / \mathrm{cm}^{2}, 86.5 \mathrm{~J} / \mathrm{cm}^{2}, 48.4 \mathrm{~J} / \mathrm{cm}^{2}, 23.1 \mathrm{~J} / \mathrm{cm}^{2}$ with a water contact angle of $12.70^{\circ}, 15.04^{\circ}, 15.87^{\circ}, 16.95^{\circ}, \quad 17.19^{\circ}$ and $38.82^{\circ}$ respectively. The transparency of pristine PS was around $90 \%$ in visible wavelength. After laser treatment, the transparency drops to $85 \%$ to $89 \%$ in the visible wavelength as shown in Fig. 7.

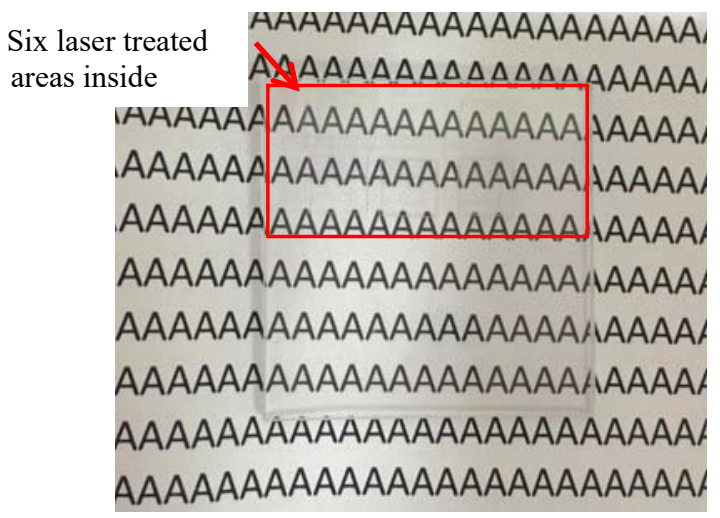

Fig. 6 Laser treated area at the fluence of $193.9 \mathrm{~J} / \mathrm{cm}^{2}, 169.5$ $\mathrm{J} / \mathrm{cm}^{2}, 130.2 \mathrm{~J} / \mathrm{cm}^{2}, 86.5 \mathrm{~J} / \mathrm{cm}^{2}, 48.4 \mathrm{~J} / \mathrm{cm}^{2}, 23.1 \mathrm{~J} / \mathrm{cm}^{2}$ (all included in the red rectangular area). Scanning speed was fixed at 200 $\mathrm{mm} / \mathrm{s}$ with a $200 \mu \mathrm{m}$ hatching density. After laser treatment the sample became highly hydrophilic (as small as $12.70^{\circ}$ ), while the material transparency was maintained.

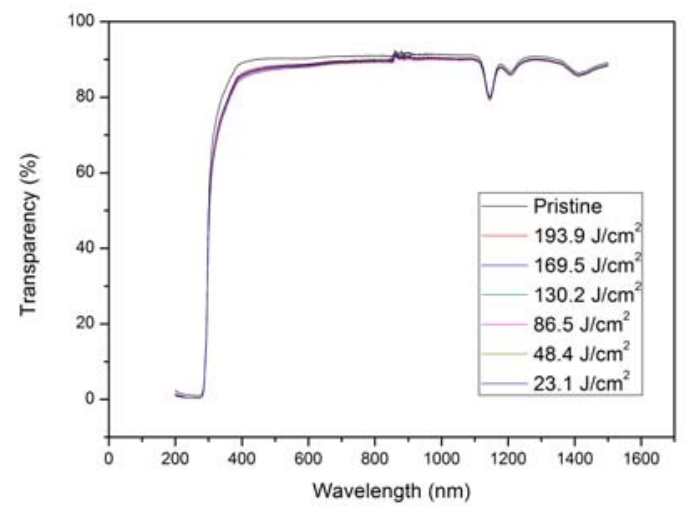

Fig. 7 Material transparency before and after laser treatment measured by a photo spectrometer (wavelength varied from 200 $\mathrm{nm}$ to $1500 \mathrm{~nm})$

It is known that oxygen-containing groups on the surface such as $\mathrm{C}-\mathrm{O}, \mathrm{C}=\mathrm{O}$, and $\mathrm{O}-\mathrm{C}=\mathrm{O}$ are responsible for the change of surface hydrophilicity [3]. To investigate this effect, X-ray photoelectron spectroscopy (XPS) analysis of chemical bonds was conducted. C1s spectra of pristine and laser treated sample at a fluence of $193.9 \mathrm{~J} / \mathrm{cm}^{2}$ were shown in Fig.9. The main peak $\mathrm{C}-\mathrm{H}$ or $\mathrm{C}-\mathrm{C}$ bond was at around $285.0 \mathrm{eV}$. The sub-peaks $\mathrm{C}-\mathrm{O}$ bond and $\mathrm{C}=\mathrm{O}$ bond were at $286.3 \mathrm{eV}$ and $288.3 \mathrm{eV}$ respectively [6]. It is known that hydrophilic surface especially super hydrophilic surface tends to reduce its hydrophilicity over time. Thus the stability of WCA of the laser treated surface was investigated over time as shown in Fig. 8. The PS surface became hydrophilic (WCA of $12.7^{\circ}$ ) after laser treatment at fluence of $193.9 \mathrm{~J} / \mathrm{cm}^{2}$, after one month the WCA recovered to $63.7^{\circ}$. This may due to the slow reaction between surface and air. Thus XPS analysis was also conducted on laser treated sample after one month. The XPS analysis shown that, the recovery of surface water contact angle was due to the decreasing of surface polar groups on the PS surface over time as presented in Table 1 . The PS sample was stored in an open air environment.

Table 1 Polar and non-polar groups formed on PS surface over time. (1) pristine PS, (2) laser treated sample at 193.9 $\mathrm{J} / \mathrm{cm}^{2}$ at 0 days and (3) laser treated sample at 193.9 $\mathrm{J} / \mathrm{cm}^{2}$ after one month.

\begin{tabular}{cccc}
\hline $\begin{array}{c}\text { Sample } \\
\text { No. }\end{array}$ & $\begin{array}{c}\text { Non-polar } \\
\text { groups C- } \\
\mathrm{C} / \mathrm{C}-\mathrm{H}(\text { at. } \%)\end{array}$ & $\begin{array}{c}\text { Sum of Polar group } \\
\mathrm{C}-\mathrm{O} \text { and C=O/O- } \\
\mathrm{C}=\mathrm{O}(\text { at.\%) }\end{array}$ & angle $\left(^{\circ}\right)$ \\
\hline 1 & 100 & - & 88.2 \\
2 & 76.28 & 23.72 & 12.7 \\
3 & 84.57 & 15.43 & 63.7 \\
\hline
\end{tabular}

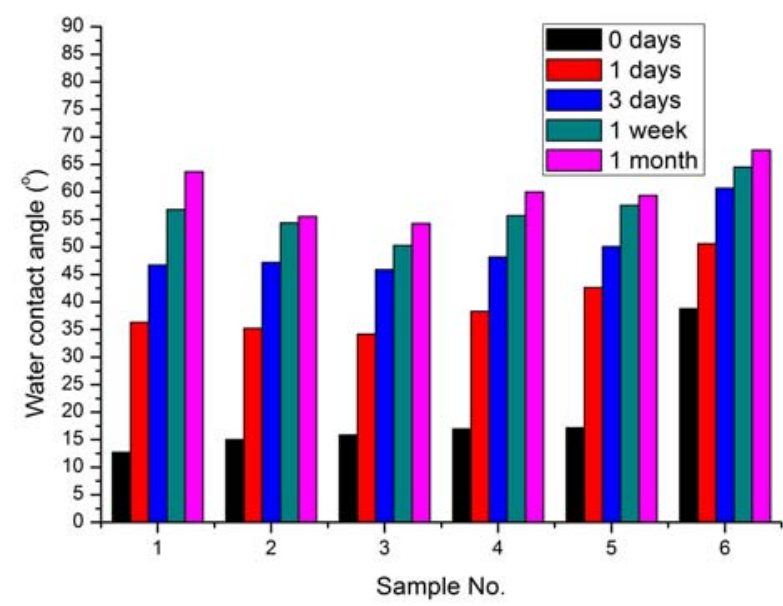

Fig. 8 Variation of WCA of laser treated sample over time. Laser treated sample at the fluence of (1) $193.9 \mathrm{~J} / \mathrm{cm}^{2}$, (2) 169.5 $\mathrm{J} / \mathrm{cm}^{2}$, (3) $130.2 \mathrm{~J} / \mathrm{cm}^{2}$, (4) $86.5 \mathrm{~J} / \mathrm{cm}^{2}$, (5) $48.4 \mathrm{~J} / \mathrm{cm}^{2}$ and (6) 23.1 $\mathrm{J} / \mathrm{cm}^{2}$. 

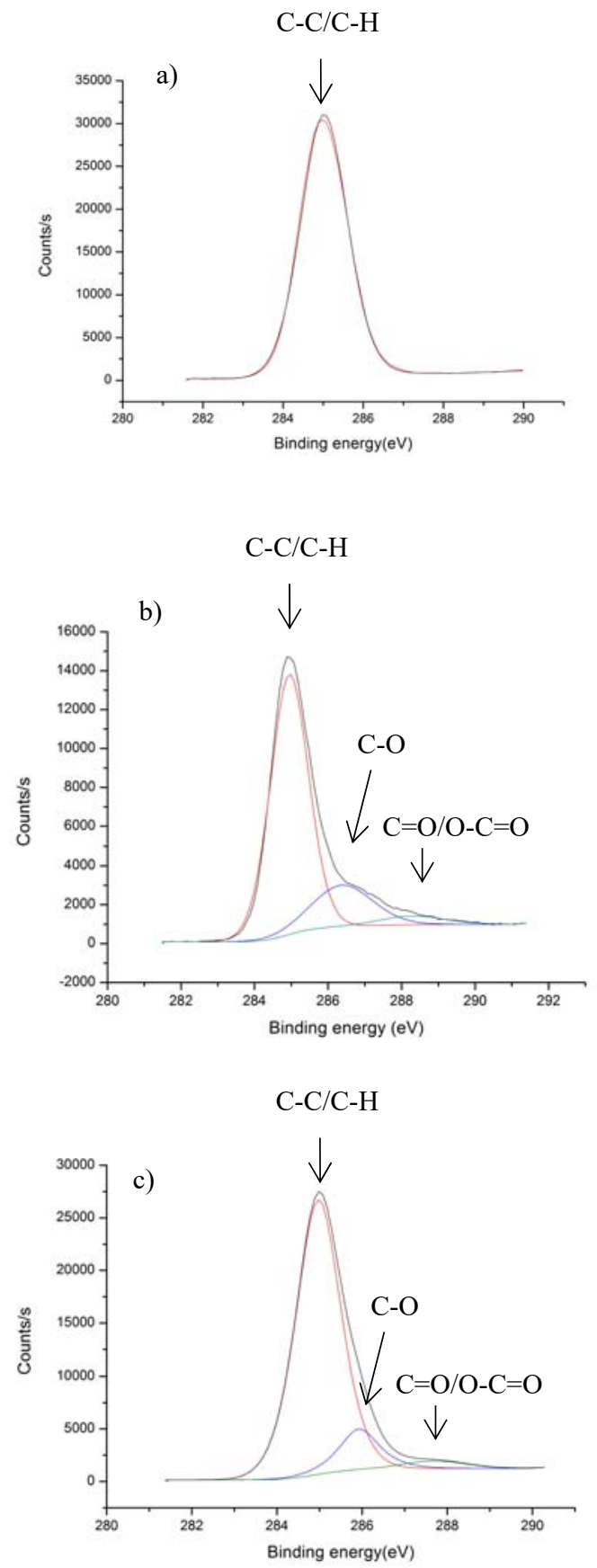

Fig. 9 XPS spectra of (a) pristine surface and (b) laser treated surface at $193.9 \mathrm{~J} / \mathrm{cm}^{2}$ and (c) laser treated surface at $193.9 \mathrm{~J} / \mathrm{cm}^{2}$ after one month.

\section{Conclusion}

A matrix of micro-pits was created on the PS surface by fs laser irradiation. The PS surface was modified to highly hydrophilic with WCA of $12.7^{\circ}$ from pristine WCA of $88.2^{\circ}$. With micro-pits created on the surface, water droplet can easily penetrate into the surface, thus the surface became hydrophilic. The substrate maintains high transparency between $85 \%$ to $89 \%$ after the laser treatment probably due to the shallow depth and low pit density. It was found that as size, depth or density of pit matrix increased, the surface became more hydrophilic which was consistent with Wenzel's model. The stability of laser treated surface over time was investigated. The recovery of WCA was found on laser treated hydrophilic surfaces, which was due to the decreasing of polar groups over time.

\section{Acknowledgments}

The authors gratefully acknowledge Singapore Institute of Manufacturing Technology under the Agency for Science, Technology and Research (A*STAR) Singapore for its financial support.

\section{References}

[1] B. Wang, X. Wang, H. Zheng, Y. Lam, Nanomaterials, 5, (2015) 1442 .

[2] Z.K. Wang, H.Y. Zheng, C.P. Lim, Y.C. Lam, Applied Physics Letters, 95, (2009).

[3] J. Lai, B. Sunderland, J. Xue, S. Yan, W. Zhao, M. Folkard, B.D. Michael, Y. Wang, Applied Surface Science, 252, (2006) 3375.

[4] T.O. Yoon, H.J. Shin, S.C. Jeoung, Y.-I. Park, Opt. Express, 16, (2008) 12715.

[5] Y. Nishi, H. Izumi, J. Kawano, K. Oguri, Y. Kawaguchi, M. Ogata, A. Tonegawa, K. Takayama, T. Kawai, M. Ochi, Journal of Materials Science, 32, (1997) 3637.

[6] S.-J. Hwang, M.-C. Tseng, J.-R. Shu, H. Her Yu, Surface and Coatings Technology, 202, (2008) 3669.

[7] T. Demina, D. Zaytseva-Zotova, M. Yablokov, A. Gilman, T. Akopova, E. Markvicheva, A. Zelenetskii, Surface and Coatings Technology, 207, (2012) 508.

[8] C.-Y. Lee, B.-S. Kim, H. Choi, J.-S. Lee, Journal of the Korean Physical Society, 63, (2013) 1399.

[9] H.J. Ramos, J.L.C. Monasterial, G.Q. Blantocas, Nuclear Instruments and Methods in Physics Research Section B: Beam Interactions with Materials and Atoms, 242, (2006) 41.

[10] J.H. Lee, H.G. Kim, G.S. Khang, H.B. Lee, M.S. Jhon, Journal of Colloid and Interface Science, 151, (1992) 563.

[11] Y. Liu, X. Yin, J. Zhang, Y. Wang, Z. Han, L. Ren, Applied Surface Science, 280, (2013) 845.

[12] A. Riveiro, R. Soto, R. Comesaña, M. Boutinguiza, J. Del Val, F. Quintero, F. Lusquiños, J. Pou, Applied Surface Science, 258, (2012) 9437.

[13] L. He, J. Chen, D.F. Farson, J.J. Lannutti, S.I. Rokhlin, Applied Surface Science, 257, (2011) 3547.

[14] V. Oliveira, B. Nunes, R. Vilar, Nuclear Instruments and Methods in Physics Research, Section B: Beam Interactions with Materials and Atoms, 268, (2010) 1626.

[15] H. Pazokian, A. Selimis, J. Barzin, S. Jelvani, M. Mollabashi, C. Fotakis, E. Stratakis, Journal of Micromechanics and Microengineering, 22, (2012).

[16] A. Ramazani S.A, S.A. Mousavi, E. Seyedjafari, R. Poursalehi, S. Sareh, K. Silakhori, A.A. Poorfatollah, A.N. Shamkhali, Materials Science and Engineering: C, 29 ,2009) 1491.

[17] F. Spano, A. Castellano, A. Massaro, D. Fragouli, R. Cingolani, A. Athanassiou, Journal of Nanoscience and Nanotechnology, 12, (2012) 4820.

[18] S.M. Eaton, C. De Marco, R. Martinez-Vazquez, R. Ramponi, S. Turri, G. Cerullo, R. Osellame, Journal of Biophotonics, 5, (2012) 687.

(Received: April 20, 2016, Accepted: June 27, 2016) 